\title{
Preregistration house officers in eight English regions: survey of quality of training
}

\author{
Jonathan H Gillard, Thomas H S Dent, Emma J Aarons, Penelope J Smyth-Pigott, \\ Michael W N Nicholls
}

\begin{abstract}
Objective-To assess the quality of preregistration house officer training in eight English regions. Design-Postal questionnaire.

Setting-Thames, East Anglian, Mersey, Northern, and Wessex regions.

Participants -1670 preregistration house officers.

Main outcome measures-Education, hours of work, workload, conditions of work, and attitudes to job and medicine as a career.
\end{abstract}

Results-Response rate was 69\% (1146 replies). Most house officers had attended induction courses $(1036 / 1129(92 \%)) ; 74 \%$ (757/1024) found them satisfactory. The proportions who had never received adequate guidance on how to break bad news and how to control pain were $59 \%(670 / 1135)$ and $56 \%$ (634/1136) respectively. There was much variation between regions. Overall, $65 \%(736 / 1138)$ reported confidence in performing cardiopulmonary resuscitation. Most respondents (95\% (1089/1142)) worked an on call rota, 3\% (36) a partial shift, and $0.6 \%$ (seven) a full shift; $19 \%$ (202) were on duty for average weekly hours that exceeded the targets for 1 April 1993. House officers had a median of 20 patients under their care and clerked a median of 10 emergency cases, six routine cases, and two day cases a week. Over half $(690 / 1128(61 \%))$ could not obtain hot food after $8 \mathrm{pm}, 20 \%(223 / 1095)$ did not always have clean sheets available in their on call room, and 45\% (462/1036) did not consider the protection of staff against violence to be adequate at their hospital. The most important problems with the preregistration year were inappropriate or nonmedical tasks (ranked first by 360 respondents), hours of work (359), and pay for out of hours work (167). Overall 57\% (646/1125) would encourage a friend to apply for their post, but only $24 \%(266 / 1112)$ would encourage a friend to take up medicine and $44 \%(494 / 1112)$ would discourage the idea.

Conclusions-House officers' training is deficient in important respects, with inappropriate tasks and heavy clinical workloads impeding the provision of proper education.

\section{Introduction}

Preregistration house officer posts were introduced in 1951 for explicit educational reasons. Calman recently suggested that the year had three main objectives: acquiring knowledge (of common medical conditions, emergencies, and rehabilitation), acquiring skills (diagnostic, clinical, and decision making), and developing attitudes (caring, learning, and ethical). ${ }^{1}$ High educational quality has, however, been difficult to achieve because of service commitments..$^{2-4}$

The responsibility for securing the educational value of these posts rests with the General Medical Council (GMC), the universities, and the licensing bodies. The GMC has a statutory obligation to recommend acceptable patterns of experience. These were last revised in 1992.5

In this study we surveyed the education and work- load of preregistration house officers in eight English regions, using the GMC's recommendations as a standard of reference when possible. We also compared house officers' responses from different regions: the University of London recently stipulated which tasks are inappropriate for preregistration house officers, ${ }^{6}$ and we wanted to see what impact this and other local initiatives had had. The survey contained questions identical to those we asked in a similar study in the Thames regions (London and the surrounding counties) four years ago, ${ }^{4}$ the comparison of the two results being reported in our previous paper. ${ }^{7}$ It also included many new questions.

\section{Method}

The survey was conducted by postal questionnaire. After a pilot study questionnaires were sent to all 1575 house officers in the Thames, East Anglian, Mersey, and Northern regions and to a randomly selected sample of 95 of the 175 house officers in the Wessex region, a total sample size of 1670 . We approached only a sample of house officers from the Wessex region because they had received several recent questionnaires on other topics and we were advised that it was not appropriate to ask them all to complete another. The first set of questionnaires were addressed to individual house officers and distributed through their clinical tutors in late November 1992. Nonrespondents were followed up by the same means in early January 1993. A third questionnaire was sent to non-respondents from the Thames regions to the address they had used when registering with the GMC.

The questionnaire requested information on the respondents' undergraduate medical education, induction courses, formal educational meetings, educational supervision, hours of duty, workload, inappropriate tasks, conditions of work, attitudes to their posts and to proposed changes in the preregistration year, and whether the respondent would recommend the post and a career in medicine to a friend. Space was provided in each section for comments. Copies of the questionnaire are available from us. Data analysis was by Pearson's $\chi^{2}$ test and Fisher's exact test unless otherwise stated.

\section{Results}

We received 1146 returned questionnaires, a response rate of $69 \%$. Regional response rates varied from $53 \%$ to $80 \%$. Not all respondents answered every question. Of the respondents, $607(53 \%)$ were men; $573(50 \%)$ were house physicians and $569(50 \%)$ house surgeons; and $891(78 \%)$ were in their first post and 236 $(21 \%)$ in their second. Overall, $1033(91 \%)$ had received clinical training in Britain.

\section{EDUCATION}

Most house officers (1036/1129 (92\%)) had attended at least one induction course, and $26 \%(267 / 1024)$ reported that their induction course was unsatisfactory. House officers were asked whether they had at any time received adequate guidance on basic and
Correspondence to:

BMF 1993;307:1180-4 
advanced cardiopulmonary resuscitation, breaking bad news, and pain control. Table I shows the results. Overall, 465 out of 1135 (41\%) house officers said that they had received adequate guidance in breaking bad news. Adequate guidance in pain control was reported by 500 out of $1135(44 \%)$. House officers who had trained overseas were less likely to report adequate training in breaking bad news (25\% (27/106) $v 43 \%$ $\left.(437 / 1027), \chi^{2}=10 \cdot 9, \mathrm{df}=1, \mathrm{p}<0.001\right)$.

House officers were asked how much time in the previous week they had spent at various types of potentially educational meetings. Table II shows results. Over half $(583 / 1116(52 \%))$ thought that there were enough meetings at their hospital. The majority $(898 / 1078(83 \%))$ were satisfied with the quality of these meetings, but 520 out of $1112(47 \%)$ were frequently or almost invariably unable to attend them because of clinical commitments.

The results varied considerably between regions, with a general trend for higher quality in the Thames regions. The proportion receiving an induction course varied from $85 \%$ to $96 \%$ between regions. House officers in the Thames regions were more likely to have attended an induction course $(94 \%(675 / 717) v 88 \%$ (359/409), $\left.\chi^{2}=13.33, \mathrm{df}=1, \mathrm{p}<0.001\right)$ and to have received training in breaking bad news $(46 \%(334 / 720)$ $\left.v 32 \%(130 / 412), \chi^{2}=23 \cdot 2, \mathrm{df}=1, \mathrm{p}<0.0001\right)$. Training in breaking bad news varied from $25 \%$ to $60 \%$ in the regions. Training in pain control was also affected by the region $\left(\chi^{2}=18.5, \mathrm{df}=7, \mathrm{p}=0.03\right)$, but variation was smaller $(20 \%$ to $51 \%)$ and training did not occur significantly more often in the Thames regions. House officers in the Thames regions were less likely to be impeded from attending educational meetings $\left(\chi^{2}\right.$ test for trend $=246, d f=4, p<0.0001)$. The proportion of house officers who invariably could not attend meetings varied from $11 \%$ to $20 \%$ between regions.

The General Medical Council stipulates that every house officer should have an educational supervisor, usually the consultant for whom the house officer is working. ${ }^{5}$ House officers were asked whether they thought that their consultant had fulfilled some of a supervisor's functions. Table III shows the results. There were no differences between the Thames regions and the other four regions.

House officers were asked how confident they were in performing basic and advanced cardiopulmonary resuscitation. Table IV shows the results. There were no significant differences between the Thames regions and the other four regions or between regions except for advanced cardiopulmonary resuscitation $\left(\chi^{2}=37 \cdot 2\right.$,

TABLE I-House officers' opinions on adequacy of guidance in important areas of practice. Values are numbers (percentages) of respondents

\begin{tabular}{lcc}
\hline & $\begin{array}{c}\text { Adequate } \\
\text { guidance }\end{array}$ & $\begin{array}{c}\text { Inadequate } \\
\text { guidance }\end{array}$ \\
\hline $\begin{array}{l}\text { Basic cardiopulmonary resuscitation }{ }^{\star}(\mathrm{n}=1139) \\
\text { Advanced cardiopulmonary resuscitation } \dagger\end{array}$ & $1037(91)$ & $102(9)$ \\
$\quad(\mathrm{n}=1135)$ & $695(61)$ & $440(39)$ \\
$\begin{array}{l}\text { Breaking bad news }(\mathrm{n}=1135) \\
\text { Pain control }(\mathrm{n}=1136)\end{array}$ & $465(41)$ & $670(59)$ \\
& $500(44)$ & $636(56)$ \\
\hline
\end{tabular}

${ }^{\star}$ Cardiac massage and assisted ventilation (mouth to mouth resuscitation and resuscitation using a bag and mask).

†Defibrillation techniques, drug treatments, and managing cardiac arrest team.

TABLE II-House officers' attendance at educational meetings. Values are numbers (percentages) of respondents

\begin{tabular}{lccc}
\hline Type of meeting & None & $\leqslant 1$ Hour & $>1$ Hour \\
\hline Audit $(n=899)$ & $660(73)$ & $111(12)$ & $128(14)$ \\
Radiology $(n=1105)$ & $463(42)$ & $544(49)$ & $98(9)$ \\
Pathology $(n=1082)$ & $861(80)$ & $209(19)$ & $12(1)$ \\
Case presentations $(n=1107)$ & $501(45)$ & $472(43)$ & $134(12)$ \\
$\begin{array}{l}\text { Main speaker drug sales representative } \\
\quad(n=1084)\end{array}$ & $639(59)$ & $404(37)$ & $41(4)$ \\
\hline
\end{tabular}

TABLE III-House officers' satisfaction with their educational supervisor. Values are numbers (percentages) of respondents

\begin{tabular}{lccc}
\hline & $\begin{array}{c}\text { Discussion of } \\
\text { responsibilities } \\
\text { of post } \\
(\mathbf{n}=1134)\end{array}$ & $\begin{array}{c}\text { Discussion of } \\
\text { problems } \\
\text { during post } \\
(\mathbf{n}=1126)\end{array}$ & $\begin{array}{c}\text { Providing } \\
\text { career } \\
\text { information } \\
(\mathbf{n}=1128)\end{array}$ \\
\hline Very satisfied & $108(10)$ & $138(12)$ & $97(9)$ \\
Satisfactory & $231(20)$ & $249(22)$ & $197(18)$ \\
Neutral & $268(24)$ & $296(26)$ & $268(24)$ \\
Dissatisfied & $310(27)$ & $281(25)$ & $306(27)$ \\
Very dissatisfied & $217(19)$ & $162(14)$ & $260(23)$
\end{tabular}

TABLE IV-House officers' confidence in performing basic and advanced cardiopulmonary resuscitation. Values are numbers (percentages) of respondents

\begin{tabular}{lcc}
\hline & $\begin{array}{c}\text { Basic } \\
(\mathrm{n}=1138)\end{array}$ & $\begin{array}{c}\text { Advanced } \\
(\mathrm{n}=1131)\end{array}$ \\
\hline Confident in performing it unsupervised & $736(65)$ & $114(10)$ \\
Less confident but would "have a go" & $390(34)$ & $660(58)$ \\
Would not perform it unless adequately supervised & $12(1)$ & $349(31)$ \\
Would refuse to perform it even if supervised & 0 & $8(1)$ \\
\hline
\end{tabular}

$\mathrm{df}=7, \mathrm{p}<0.001)$. House officers who had been trained overseas were less likely to report adequate training in basic cardiopulmonary resuscitation $(82 \%(89 / 108) v$ $\left.92 \%(946 / 1029), \chi^{2}=9 \cdot 73, \mathrm{df}=1, \mathrm{p}<0.01\right)$.

\section{HOURS OF WORK}

Most respondents $(1089 / 1142(95 \%))$ worked on call rotas, $36(3 \%)$ worked partial shifts, and seven $(0 \cdot 6 \%)$ worked full shifts. Of those working on call rotas, 202 out of $1043(19 \%)$ reported that they were officially on duty for more than 83 hours a week (the NHS Management Executive's target for 1 April 1993'); 58 $(6 \%)$ were on duty for more than 90 hours a week and $643(62 \%)$ for more than 72 . There were no differences between regions. Five out of 35 doctors (14\%) working partial shifts who stated their hours on duty were on duty for more than 72 hours a week, the target for 1 April 1993. When they were on duty outside normal working hours those working on call rotas spent a median of three quarters of their time working rather than sleeping, eating, watching television, reading, etc; most of them $(868 / 1084(80 \%))$ said that they were working more than half the time. A fifth of respondents (223/1131) were working maximum continuous periods of duty of 80 hours, equivalent to a three day weekend ( 9 am Friday to $5 \mathrm{pm}$ Monday). Such rotas were more common in the Thames regions $\left(23 \% v 13 \%, \chi^{2}=15 \cdot 1\right.$, $\mathrm{df}=1, \mathrm{p}<0.0001)$. Even a two day weekend amounting to 56 continuous hours was enough for one house officer to report, "I have never provided the sort of care patients deserve on a Monday after a weekend on call." When they were not on duty overnight house officers worked a median of nine hours a day.

\section{WORKLOAD}

The median number of patients whom respondents had under their care was 20 (range 1 to 80). Only 103 out of $1133(9 \%)$ had more than 30 patients, previously suggested by the GMC as a maximum. ${ }^{9}$ They clerked a median of 10 patients admitted as emergencies, six patients admitted routinely, and two patients admitted as day cases per week; only 77 out of $1000(8 \%)$ clerked more than 10 patients admitted as day cases in an average week. Most (679/1127 (60\%)) thought that they were gaining the right amount of clinical experience, $146(13 \%)$ that they were seeing too few patients to gain sufficient clinical experience, and 277 $(25 \%)$ that they were seeing so many that they did not have time to learn from their job. The median number of patients under the care of house officers who thought they were seeing the right number of patients was 19 , compared with 23 for those who thought they were seeing too many and 15 for those who thought they 
were seeing too few; the median numbers of all weekly admissions (routine, emergency, and day case) in these three categories were respectively 20,22 , and 13 .

The median number of wards in which the respondents had patients was three (range 1 to 13). A quarter (280/1138) had easy access to the results of investigations by computer. Half $(581 / 1129(51 \%))$ provided care to private patients and 61 out of $579(11 \%)$ had received or expected to receive payment for this work.

House officers were asked their views about the amount of time spent on inappropriate tasks, such as conveying patients, requests for investigations and samples around the hospital, and chasing results. Table V shows the results. They were asked who was responsible for taking routine blood samples, giving intravenous drugs other than first doses, filing results, and finding beds for emergency admissions between 9 am and $5 \mathrm{pm}$. Table VI shows the results, including comparisons between the Thames regions and the other four regions.

CONDITIONS OF WORK

Most respondents (1094/1137 (96\%)) were receiving or had completed a course of hepatitis B vaccination. Over half of the house officers $(690 / 1128(61 \%))$ did not have hot food available after $8 \mathrm{pm}$ and a fifth $(223 / 1095$ $(20 \%)$ ) did not always have clean sheets available in their on call room. Around $40 \%$ did not consider the protection of their possessions against theft (468/1107 $(42 \%))$ or the protection of staff against violence (462/ $1036(45 \%))$ to be adequate at their hospital. The

TABLE V-House officers' perceptions of amount of time spent carrying out inappropriate tasks. Values are numbers (percentages) of respondents

\begin{tabular}{lcc}
\hline & $\begin{array}{c}\text { Conveying patients, } \\
\text { results, and samples } \\
(\mathrm{n}=1137)\end{array}$ & $\begin{array}{c}\text { Chasing results } \\
(\mathrm{n}=1131)\end{array}$ \\
\hline Reasonable & $231(20)$ & $98(9)$ \\
Acceptable & $235(21)$ & $219(19)$ \\
Moderate & $259(23)$ & $328(29)$ \\
Excessive & $294(26)$ & $348(31)$ \\
Grossly excessive & $118(10)$ & $138(12)$ \\
\hline
\end{tabular}

TABLE VI-Comparison between Thames regions and other four regions of who is responsible for various tasks. Values are numbers or proportions (percentages) of respondents *

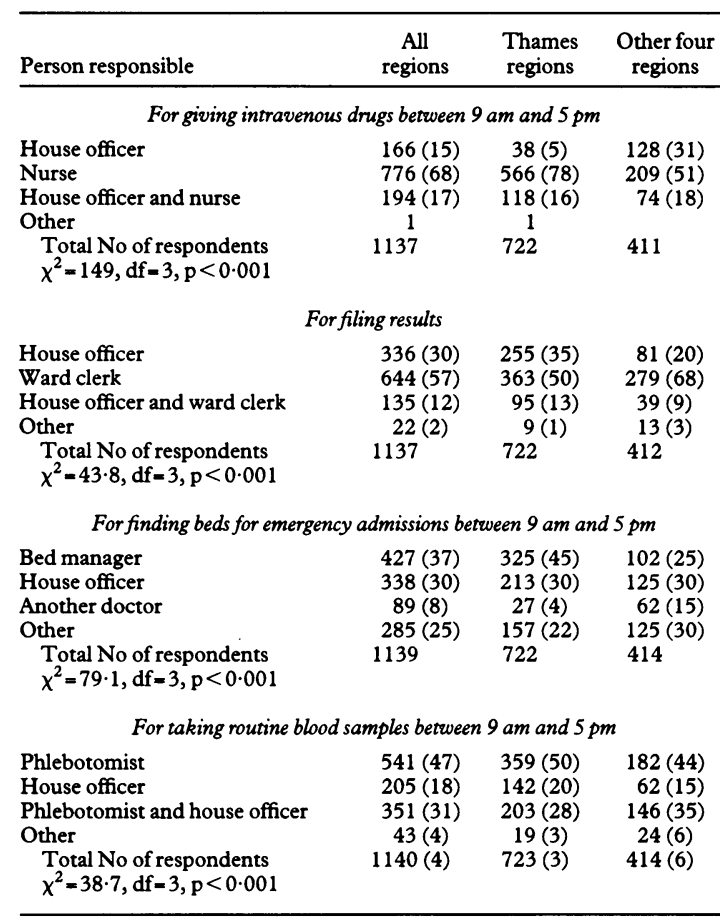

*Three respondents removed details of their region from their questionnaire. They are included under all regions but not under Thames or other four regions.
TABLE VII-House officers' views on proposed changes to preregistration year. Values are numbers (percentages) of respondents

\begin{tabular}{lcc}
\hline & $\begin{array}{c}\text { Include four months } \\
\text { of general practice } \\
(\mathrm{n}=1120)\end{array}$ & $\begin{array}{c}\text { Extend year to two years } \\
\text { for structured training } \\
(\mathrm{n}=1114)\end{array}$ \\
\hline Strongly agree & $125(11)$ & $92(8)$ \\
Agree & $133(12)$ & $154(14)$ \\
Neutral & $174(16)$ & $164(15)$ \\
Disagree & $236(21)$ & $206(19)$ \\
Strongly disagree & $452(40)$ & $498(45)$ \\
\hline
\end{tabular}

TABLE VII-Extent to which house officers would encourage a friend to apply for their post and a family friend to consider career in medicine. Values are numbers (percentages) of respondents

\begin{tabular}{lcc}
\hline & $\begin{array}{c}\text { Friend to apply } \\
\text { for post } \\
(\mathrm{n}=1125)\end{array}$ & $\begin{array}{c}\text { Family friend to consider } \\
\text { medical career } \\
(\mathrm{n}=1112)\end{array}$ \\
\hline Strongly encourage & $266(24)$ & $90(8)$ \\
Encourage & $380(34)$ & $176(16)$ \\
Neutral & $270(24)$ & $352(32)$ \\
Discourage & $126(11)$ & $279(25)$ \\
Strongly discourage & $83(7)$ & $215(19)$ \\
\hline
\end{tabular}

degree of concern about theft was not different between regions, but house officers in the Thames regions were less satisfied with precautions against violence $\left(51 \%(337 / 661) v 63 \%(236 / 372), \chi^{2}=14 \cdot 5\right.$, $\mathrm{df}=1, \mathrm{p}<0.001)$.

\section{ATTITUDES}

House officers were asked to rank a series of problems affecting the house officer year according to importance in their job. Inappropriate or non-medical tasks were ranked as most important by 360 out of 982 $(37 \%)$ of respondents who ranked it at all, hours of work by 359 out of 935 (38\%), and pay for work outside normal working hours by 167 out of $888(19 \%)$. No other problem was ranked first by more than 100 respondents. These results showed no difference between regions.

House officers were asked whether the preregistration year should include four months of training in general practice and whether the training should be extended to two years to provide time for structured training, a new idea. ${ }^{10}$ Table VII shows the results. Our final questions were whether they would recommend their job to a friend and encourage a friend of the family to take up medicine as a career. Table VIII shows the results. There were no differences between regions in the responses to these questions except in whether house officers would recommend their posts to a friend $\left(x^{2}=72 \cdot 6, \mathrm{df}=7, \mathrm{p}<0.001\right)$, and there were no differences between the Thames regions and the other four regions. The proportion of respondents who would strongly encourage a friend to apply for their posts varied from $13 \%$ to $31 \%$, both extremes being among house officers in the four regions outside the Thames regions. Women tended to be more likely to recommend their post to a friend $\left(\chi^{2}\right.$ for trend $=6 \cdot 74, \mathrm{df}=4$, $p<0.01$ ), but they were neither more nor less likely than men to recommend medicine as a career.

\section{Discussion}

EDUCATION

House officers value their educational meetings, and nearly half would like more formal educational sessions. A house officer commented, "Nobody seems to take a real and interested responsibility for junior staff education." Many house officers, however, are still prevented from attending by clinical tasks and "Even if you do get to the meetings, you almost always get bleeped out of them." Audit meetings are commonly held less often than once a week and therefore more house officers than are shown in table II probably attend them regularly, perhaps once or twice a month. 
Training in cardiopulmonary resuscitation remains a serious cause for concern. Only $65 \%$ of house officers were confident in performing cardiopulmonary resuscitation and the proportion who are proficient is probably much lower. ${ }^{.1}$

The efforts of the University of London to safeguard house officers' education from overwhelming clinical pressures may explain why house officers in the Thames regions were more likely to attend educational meetings and induction courses. Few consultants in any region, however, have impressed their house officers with their commitment to educational supervision. One house officer wrote, "My consultants have not given me any formal teaching. I have hardly been to theatre to assist in elective cases because of ward commitments ... I have had lack of support from the registrars because they are either in clinic or theatre. I am usually in A and E [accident and emergency] alone... There are so many patients to look after and they are often acutely ill." Consultants are willing to increase their participation in training house officers, but lack skills and time and do not see the preregistration year as an educational process. ${ }^{12}$ Both consultants and house officers probably lack knowledge of what the GMC expects. ${ }^{13}$ Consultants give more emphasis to the importance of their teaching than do their junior staff: in a postal questionnaire survey $55 \%$ of senior house officers cited consultant ward rounds as one of the five learning methods on which they relied, whereas $84 \%$ of consultants believed that senior house officers relied most on ward rounds for learning. ${ }^{14}$

\section{WORKLOAD AND HOURS OF WORK}

House officers reported spending an excessive amount of time on non-medical tasks and regard this as the most serious deficiency of their posts. One house officer reported, "Most of my job could be done by clerical staff."

The NHS Management Executive intended that no doctor working an on call rota should be on duty for more than 83 hours a week after 1 April $1993 .{ }^{8}$ Unless progress was dramatic in the short time since our fieldwork, the target was not achieved for at least $19 \%$ of the house officers surveyed. Even when contracted hours are within these prescribed limits, the extent of early starts and late finishes (indicated by a median duration of the house officers' working day of nine hours) suggests that actual hours on duty still exceed these limits. By the end of 1994 no doctor working an on call rota should be on duty more than 72 hours a week. This will require further reductions in hours in $62 \%$ of house officer posts.

Eighty per cent of those working on call rotas said that they were working more than half the time that they were on duty out of hours, leaving less than eight hours for sleep in an overnight spell of 16 hours. Posts in which the intensity of on call work means that there is no "reasonable expectation" of eight hours' sleep in each overnight spell are regarded as unsuitable for on call rotas. ${ }^{8}$ On call duties will therefore need to be reduced (by a nurse practitioner performing some tasks at night, for example ${ }^{15}$ ). In special circumstances partial shifts may be appropriate, although reported successes are rare. ${ }^{1617}$ The University of London has recently recommended that on call rotas should provide the normal pattern of preregistration training. ${ }^{18}$

\section{CONDITIONS OF WORK}

House officers are usually not able to obtain hot food ater $8 \mathrm{pm}$; a fifth of respondents slept in sheets that had not been changed on some of the nights that they were on call.

The threats of theft and of violence alarm some house officers, for reasons that hospitals could perhaps

\section{Educational implications}

- There are serious deficiencies in the preparation of preregistration house officers for their role and in the education they receive in post, with large variations between regions and the Thames regions performing better on several measures

- This study found that the most important problems that house officers report are inappropriate tasks and excessive hours of work

- More than half of the house officers had never received adequate guidance in pain control and in breaking bad news, and more than a third were not confident in performing basic cardiopulmonary resuscitation unsupervised, with house officers overseas trained reporting more problems with the latter two activities

- Eighty per cent of house officers working on call rotas have intensities of work which should mean they work partial shifts, and $20 \%$ are still working three day weekends

- Only $24 \%$ of house officers would recommend a career in medicine to a friend, and $44 \%$ would discourage it

overcome. One house officer wrote, "Walking to my on call room at night, through relatively unlit areas of a car park infamous for its theft, I am often scared and appalled by the inadequate protection offered. Porters and other staff refuse to accompany me; although I have complained, it is to no avail."

House officers in the Thames regions are less likely than those elsewhere to take blood samples and administer intravenous drugs routinely, but ward clerks to file results are more common outside the Thames regions. The greater presence of bed managers in the Thames regions has reduced the need for fully registered doctors but not house officers to find beds during the day. We have no data on what happens outside normal working hours, when most emergency admissions occur and bed managers are seldom on duty. House officers take a lot of routine blood samples, but there is no clear difference between the Thames regions and the other four regions. These differences may be partially attributable to the strict stipulations of the University of London about inappropriate duties for house officers. ${ }^{6}$ The stipulations have not, however, produced any differences in house officers' perceptions of what their main problems are. The gain from allocating these tasks more appropriately is clinical as well as educational: when nurses rather than doctors give intravenous antibiotics the timing and recording of doses improve. ${ }^{19}$

\section{ATTITUDES}

House officers are against training in general practice during the preregistration year. One house officer commented that she liked the idea of such training but "four months of medicine would not be adequate time to gain confidence and experience." Dowie recommended that preregistration training in general practice should be more widely available. ${ }^{20}$ She suggested that it would be less stressful than the equivalent period in hospital and provide experience of caring for patients with chronic diseases in the community; this experience would be particularly valuable for doctors planning careers in hospital medicine.

House officers are even more decisively against lengthening the preregistration period. One remarked, "I think many people would give up medicine rather than do another house officer year." These findings 
accord with the view that longer preregistration training would exacerbate the problems house officers face..$^{21}$ Less than a quarter of respondents would encourage potential medical students to enter the profession, although over half would recommend their job to a friend.

\section{CONCLUSION}

There are serious deficiencies in the preparation of house officers for their role and in the education they receive in post. They are often subject to excessive and inappropriate demands, working rotas incompatible with NHS Management Executive targets in hospitals that many of them regard as insecure. Unsurprisingly, few house officers would encourage others to take up medicine.

We thank the house officers who completed our questionnaire; the clinical tutors and their staff who distributed it; Professors John Anderson and Peter Flute and Drs Trevor Bailey, John Biggs, Hugh Platt, Elizabeth Shore, and Jack Tinker who gave us permission to survey their regions; Julie DeSimon who coordinated the fieldwork; and Dr R C King who inspired these projects. We also thank Julian Lipscombe for entering data.

1 Calman KC. The preregistration year. In: Downie RS, Charlton B, eds. The making of a doctor: medical education in theory and practice. Oxford: Oxford University Press, 1992.

2 McManus IC, Lockwood DNJ, Cruickshank JK. The preregistration year: chaos by consensus. Lancet 1977; i:413-6.

3 Christie RAS. The preregistration house appointment: a survey in Manchester. Med Educ 1980;14:210-3.
4 Dent THS, Gillard JH, Aarons EJ, Crimlisk HL, Smyth-Pigott PJ. Preregistration house officers in the four Thames regions. I. Survey of education and workload. $B M Y$ 1990;300:713-6.

5 General Medical Council. Recommendations on general clinical training. London: GMC, 1992.

6 University of London. The preregistration year: inappropriate duties for preregistration house officers. London: University of London, 1990.

7 Gillard JH, Dent THS, Aarons EJ, Crimlisk HL, Smyth-Pigott PJ, Nicholls $M W N$. Preregistration house officers in the Thames regions: changes in quality of training after four years. $B M F$ 1993;307:1176-9.

8 NHS Management Executive. Doctors and dentists in training: terms and conditions of service/model contract guidance (HSG (93) 1). London: NHSME 1993.

9 General Medical Council. Recommendations on general clinical training. London: GMC, 1987.

10 Richards $P$. Educational improvement of the preregistration period of general clinical training. $B M 7$ 1992;304:625-7.

11 Morris F, Tordoff SG, Wallis D, Skinner DV. Cardiopulmonary resuscitation skills of preregistration house officers: five years on. $B M \mathcal{F}$ 1991;302:626-7.

12 Wilson DH. Education and training of preregistration house officers: the consultants' viewpoint. $B M^{\mathcal{F}}$ 1993;306:194-6.

13 Dowling S, Barrett S. Doctors in the making: the experience of the preregistration year. Bristol: School for Advanced Urban Studies, 1992

14 Grant J, Marsden P, King RC. Senior house officers and their training. I Personal characteristics and professional circumstances. II. Perceptions of service and training. $B M 7$ 1989;299:1263-8.

15 Lowry S. The preregistration year. BMf 1993;306:196-8.

16 Vassallo DJ, Chana J, Clark CL, Smith RE, Wood RF. Introduction of a partial shift system for house officers in a teaching hospital. $B M$ 1992;305:1005-8.

17 Nasmyth DG, Pickersgill A, Hogarth M. Reducing hours of work of

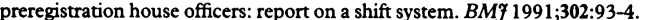

18 University of London. House of work-the preregistration year. London: University of London, 1993.

19 Denton M, Morgan MS, White RR. Quality of prescribing of intravenous antibiotics in a district general hospital. $B M \mathcal{F} 1991 ; 302: 327-8$.

20 Dowie R. Patterns of hospital medical staffing: overview. London: HMSO, 1991

21 Dowie R. Patterns of hospital medical staffing: overview. London: HMSO, 1991. 1992;48:215-7.

(Accepted 8 September 1993)

\section{Heterosexual transmission of HIV in injecting drug users}

\section{Edinburgh Drug Addiction Study, Edinburgh EH4 4PL Peter J M Ronald, research associate \\ J R Robertson, general practitioner}

\section{MRC Heterosexual}

Transmission Study,

Edinburgh EH4 4PL

$\mathrm{R}$ Wyld, research nurse

$\mathrm{R}$ Weightman, research nurse

Correspondence to:

Dr Robertson.

BMF 1993;307:1184-5

Annual incidence of HIV infection among 440 injecting drug users from 1982 to 1993

\begin{tabular}{ccc}
\hline & \multicolumn{2}{c}{$\begin{array}{c}\text { No of seroconversions } \\
\text { attributed to: }\end{array}$} \\
\cline { 2 - 3 } & $\begin{array}{c}\text { Shared } \\
\text { injecting }\end{array}$ & $\begin{array}{c}\text { Heterosexual } \\
\text { intercourse }\end{array}$ \\
\hline Year & equipment & 0 \\
1982 & 0 & 0 \\
1983 & 76 & 0 \\
1984 & 49 & 0 \\
1985 & 30 & 0 \\
1986 & 9 & 0 \\
1987 & 0 & 3 \\
1988 & 0 & 2 \\
1989 & 0 & 0 \\
1990 & 0 & 0 \\
1991 & 0 & 0 \\
1992 & 0 & 2 \\
1993 & 0 & 1 \\
\hline Total & 164 & 8 \\
\hline
\end{tabular}

\section{Peter J M Ronald, J R Robertson, R Wyld, R Weightman}

The rapid rise in the prevalence of HIV infection among injecting drug users during the early 1980 s in Edinburgh was attributed to sharing injecting equipment. ${ }^{1}$ More recently injecting drug users in Edinburgh and other British cities have reduced their high risk behaviour, ${ }^{23}$ probably because of increased awareness of the risks of infection. We investigated whether seroconversion attributable to injecting behaviour had also declined in this population since the mid-1980s.

\section{Subjects, methods, and results}

In a longitudinal study of 440 injecting drug users 172 (119 men) were positive for HIV antibodies and 148 (104 men) were negative; 120 (86 men) were not tested for various reasons. Dates of seroconversion were estimated for the 172 infected subjects as the midpoint between the dates of the last test giving negative results for HIV antibodies and the first giving positive results. If the date of the last negative test was unknown we used 1 January 1983, which has been calculated as the first possible date that HIV could have been transmitted in Edinburgh. ${ }^{4}$ Seroconversion was attributed either to sharing infected injecting equipment or to heterosexual intercourse between injecting drug users. The mode of transmission was determined from self reported data obtained during follow up, from medical records, and from medical staff concerned with the patients' care.

The table shows that the incidence of HIV infection attributable to sharing injecting equipment reached a peak in 1983 but then declined rapidly. From 1987 none of the eight seroconversions was attributable to sharing injecting equipment: all were attributable to unprotected heterosexual intercourse.

\section{Comment}

Although the annual incidence of HIV among injecting drug users has been low since 1987, it represents the emerging problem of heterosexual transmission of HIV. These rates probably underestimate the true incidence of sexually transmitted HIV infection for injecting drug users because we have not followed up any of their heterosexual contacts who do not inject drugs. There are virtually no recorded homosexual relationships in this group.

In the early ' 80 s attention was focused on transmission of HIV by sharing injecting equipment. Transmission among injecting drug users who admitted sharing may have been attributed solely to drug use without considering heterosexual intercourse as an alternative cause. The uncertainty surrounding this issue is compounded by the reliance on self reported information.

Despite national and local campaigns to educate the public about the risks of unprotected heterosexual intercourse the regular use of condoms remains low. Even those couples at highest risk because one partner is positive for HIV often continue to have unprotected sex, possibly often with a view to achieving pregnancy ( $\mathrm{R}$ Wyld et al, seventh international conference on AIDS, Florence, 1991). People generally seem unconvinced about the risks of heterosexual transmission. They receive conflicting messages, and information campaigns are undermined as members of the public increasingly gain personal experience of couples who do not practise safe sex without transmitting HIV.

HIV has already been transmitted to the next generation in the United Kingdom. ${ }^{5}$ In Scotland most heterosexual transmission has occurred among sexual contacts of injecting drug users. If an epidemic of HIV 